\title{
The comparative physiological ecology of vertebrates: essays in honor of Mario Rosenmann
}

\author{
FRANCISCO BOZINOVIC
}

Center for Advanced Studies in Ecology \& Biodiversity and Departamento de Ecología, Facultad de Ciencias Biológicas, Pontificia Universidad Católica de Chile, Santiago 6513677, Chile

Dr. Mario Rosenmann Abramovich (1933-2004) passed away. With the passing of our dear friend and outstanding researcher and professor, we should think about his wonderful life, which he lived to the fullest. We should also remember how Mario enriched our lives.

Mario Rosenmann Abramovich was born and raised in Santiago, Chile. $\mathrm{He}$ attended the Universidad

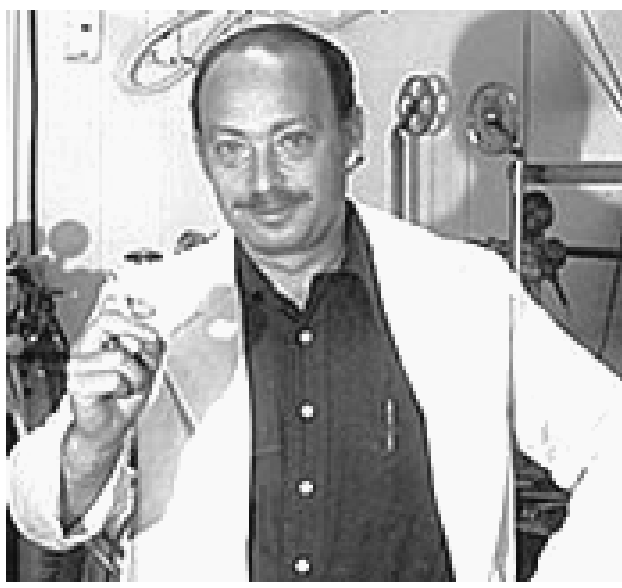
de Chile as an undergraduate in biology. During this period, he fell under the influence of the zoologist Guillermo Mann, Director of the Center of Zoological Research at the Universidad de Chile and many collaborators, who seduced him into an interest of the principles of animal physiology and the myriads of physiological mechanisms that animals have. Specifically, Mario started his studies with camelids in the Chilean altiplano.

Spurred by his interest in comparative physiology, Mario did a Ph.D. under the supervision of Peter Morrison at the University of Alaska in USA, and he defended his thesis entitled "a comparative study of metabolic response of small mammals to selected enviromental factors: hypoxia, cold and visual disturbance". He returned to the Universidad de Chile in 1974 and became Full Professor. Mario knew of no taxonomical bounds and he asked questions on a variety of topics. $\mathrm{He}$ studied energetics and thermoregulation in Mediterranean rodents and marsupials, hypoxia and hematology of toads, rodents, birds, lizards and fishes from different habitats, circadian rhythms in rodents, mechanisms of acclimation and acclimatization to different environmental cues, including human-induced ones. In short, he worked on virtually every topic and species of vertebrate imaginable.

During his years at the Departmento de Ciencias Ecológicas at the Facultad de Ciencias, Universidad de Chile, he established an impressively active laboratory of comparative physiology, he developed an internationally recognized research program, and produced a remarkable list of publications. This list is not only long, but impressive in scope and depth. He organized a Ph.D Program in Zoology, dedicated a large amount of time to administration, and graduated many M.Sc. and Ph.D. students.

Mario had an engaging and attractive personality. He possessed a vast store of jokes and anecdotes that he shared generously. His sense of humor was legendary. His students leaned not only about comparative physiology but also about the joy of science as a collective enterprise. He was not only a teacher, but a complete mentor who nurtured both the intellectual and the personal lives of his students. During these last years, his administrative duties distracted him from science but benefited the academic community enormously. In spite of his administrative commitments, Mario continued to pursue his interest in metabolic adaptation, hematology and osmoregulation. He also continued to advise many undergraduate and graduated students.

Mario was an accomplished scientist and a fine gentleman. He will always be sorely missed. One year after Mario Rosenmann passed away, this issue of the Revista Chilena de Historia Natural, dealing with different topics in comparative physiological ecology of vertebrates, honors his memory. 